\title{
Targeting CDC7 potentiates ATR-CHK1 signaling inhibition through induction of DNA replication stress in liver cancer
}

Yuchen Guo ${ }^{1,2+}$, Jun Wang ${ }^{1 \dagger}$, Bente Benedict ${ }^{3 \dagger}$, Chen Yang ${ }^{1 \dagger}$, Frank van Gemert ${ }^{3}$, Xuhui Ma ${ }^{1}$, Dongmei Gao ${ }^{4}$, Hui Wang ${ }^{1}$, Shu Zhang ${ }^{4}$, Cor Lieftink², Roderick L. Beijersbergen², Hein te Riele ${ }^{3}$, Xiaohang Qiao ${ }^{3}$, Qiang Gao ${ }^{4}$, Chong Sun ${ }^{5}$, Wenxin Qin ${ }^{1}$, René Bernards ${ }^{1,2^{*}}$ (D) and Cun Wang ${ }^{1 *}$

\begin{abstract}
Background: Liver cancer is one of the most commonly diagnosed cancers and the fourth leading cause of cancerrelated death worldwide. Broad-spectrum kinase inhibitors like sorafenib and lenvatinib provide only modest survival benefit to patients with hepatocellular carcinoma (HCC). This study aims to identify novel therapeutic strategies for HCC patients.

Methods: Integrated bioinformatics analyses and a non-biased CRISPR loss of function genetic screen were performed to identify potential therapeutic targets for HCC cells. Whole-transcriptome sequencing (RNA-Seq) and time-lapse live imaging were performed to explore the mechanisms of the synergy between CDC7 inhibition and ATR or CHK1 inhibitors in HCC cells. Multiple in vitro and in vivo assays were used to validate the synergistic effects.

Results: Through integrated bioinformatics analyses using the Cancer Dependency Map and the TCGA database, we identified ATR-CHK1 signaling as a therapeutic target for liver cancer. Pharmacological inhibition of ATR or CHK1 leads to robust proliferation inhibition in liver cancer cells having a high basal level of replication stress. For liver cancer cells that are resistant to ATR or CHK1 inhibition, treatment with CDC7 inhibitors induces strong DNA replication stress and consequently such drugs show striking synergy with ATR or CHK1 inhibitors. The synergy between ATR-CHK1 inhibition and CDC7 inhibition probably derives from abnormalities in mitosis inducing mitotic catastrophe.
\end{abstract}

Conclusions: Our data highlights the potential of targeting ATR-CHK1 signaling, either alone or in combination with CDC7 inhibition, for the treatment of liver cancer.

Keywords: Hepatocellular carcinoma, ATR-CHK1 signaling, Replication stress, Cell division cycle 7

\footnotetext{
* Correspondence: r.bernards@nki.nl; cwang@shsci.org

${ }^{\dagger}$ Yuchen Guo, Jun Wang, Bente Benedict and Chen Yang contributed equally to this work.

'State Key Laboratory of Oncogenes and Related Genes, Shanghai Cancer Institute \& Department of Liver Surgery, Renji Hospital, Shanghai Jiao Tong University School of Medicine, Shanghai, China

Full list of author information is available at the end of the article
}

(C) The Author(s). 2021 Open Access This article is licensed under a Creative Commons Attribution 4.0 International License, which permits use, sharing, adaptation, distribution and reproduction in any medium or format, as long as you give appropriate credit to the original author(s) and the source, provide a link to the Creative Commons licence, and indicate if changes were made. The images or other third party material in this article are included in the article's Creative Commons licence, unless indicated otherwise in a credit line to the material. If material is not included in the article's Creative Commons licence and your intended use is not permitted by statutory regulation or exceeds the permitted use, you will need to obtain permission directly from the copyright holder. To view a copy of this licence, visit http://creativecommons.org/licenses/by/4.0/. The Creative Commons Public Domain Dedication waiver (http://creativecommons.org/publicdomain/zero/1.0/) applies to the data made available in this article, unless otherwise stated in a credit line to the data. 


\section{Background}

Liver cancer poses a significant threat to human health, as it is one of the most lethal cancer types with a 5-year survival of only $18 \%$ [1]. The histological subtype of the majority of liver cancer cases is hepatocellular carcinoma (HCC). Sorafenib, a multi-kinase inhibitor approved by US Food and Drug Administration (FDA) as the standard therapy for advanced HCC patients in 2007, only provides less than 3-months benefit in median overall survival [2]. Many systematic therapies, including lenvatinib [3], regorafenib [4], cabozantinib [5], pembrolizumab [6] and nivolumab $[7,8]$, have currently been approved by FDA for the treatment of late-stage or unresectable HCC patients. Most of them, however, only provide limited survival benefit $[9,10]$. The recent IMbrave150 trial indicates that the combination of atezolizumab and bevacizumab resulted in better survival outcomes than sorafenib monotherapy, providing a confirmed objective response rate of 27.3\% [11]. Despite this progress, further investigations of novel therapeutic strategies are urgently required to counter this lethal disease.

ATR and CHK1 were identified as potential therapeutic targets for cancer. ATR-CHK1 signaling is a key regulator of the DNA damage response (DDR) involved in sensing DNA replication stress due to oncogene activation or impairment of G1 checkpoint regulation [12, 13]. Given the broad role of ATR-CHK1 signaling in the DDR, development of ATR and CHK1 inhibitors has received considerable attention from oncology drug developers. Although ATR and CHK1 inhibitors have shown anti-tumor effects as monotherapy in preclinical studies, the clinical effects of these drugs most likely will be dependent on using the right combination therapies and biomarkers-guided patient classification [12, 14-20]. It has been demonstrated that ATR and CHK1 inhibitors can potentiate the efficacy of genotoxic chemotherapies, such as doxorubicin, irinotecan, and gemcitabine, which are strong inducers of DNA damage [12, 14-16]. Several studies have suggested that tumor cells with high levels of DNA replication stress (overexpressing replication stress-inducing oncogenes such as RAS, CCNE1 or $M Y C$ ), genetic deficiencies in TP53 or ATM, or defects in homologous recombination, will likely be more vulnerable to ATR inhibitors [17-20]. In liver cancer, however, despite some preliminary findings [21-23], the therapeutic benefit of ATR and CHK1 inhibitors remain to be explored.

The cell division cycle 7 (CDC7) protein plays key roles in DNA replication initiation, the S-phase checkpoint, and M-phase completion [24]. CDC7 expression is upregulated in HCC tumor tissues relative to paired non-tumor tissues, which provides a potential therapeutic window for cancer treatment [25]. Bioavailable selective CDC7 inhibitors (TAK-931 and LY3143921) [26, 27] have recently entered phase I clinical trials in patients with advanced solid tumors. It has been reported that inhibition of CDC7 significantly reduces replication fork initiation and then induces replication stress $[28,29]$.

Here, we use integrated bioinformatics and functional genetics approaches to study the therapeutic options for the use of ATR or CHK1 inhibitors in liver cancer. Our study provides a potential classification and treatment strategy for liver cancer patients based on DNA replication stress levels of tumor tissues.

\section{Methods}

\section{Human cell lines}

The human HCC cell lines, Hep3B, Huh7, SNU182, PLC/ PRF/5, SNU398, HepG2, Huh6, and SNU449 were provided by Erasmus University (Rotterdam, Netherlands). MHCC97H was provided by the Liver Cancer Institute of Zhongshan Hospital (Shanghai, China). HCC cells were cultured in Dulbecco's Modified Eagle Medium (DMEM) with $10 \%$ fetal bovine serum, glutamine, and penicillin/ streptomycin (Gibco) at $37^{\circ} \mathrm{C} / 5 \% \mathrm{CO}_{2}$. Mycoplasma contamination was excluded via a PCR-based method. The identities of all the cell lines were confirmed by short tandem repeat (STR) profiling.

\section{Compounds and antibodies}

AZD6738 (S7693), MK-8776 (S2735), XL413 (S7547), LY3177833 (206762), BAY-1895344 (S8666), LY2606368 (S7178), Cisplatin (S1166), and Z-VAD-FMK (S7023) were purchased from Selleck Chemicals. XL413 (205768) and AZD6738 (206114) were purchased from MedKoo Bioscience. TAK-931 (CT-TAK931) was purchased from Chemietek. Antibodies against HSP90 (sc-7947, sc-13119), Cyclin B1 (sc-245), ATR (sc-515173), and CHK1 (sc-8408) were purchased from Santa Cruz Biotechnology. Antibody against $\gamma \mathrm{H} 2 \mathrm{AX}$ (05-636-AF647) was purchased from Merck Millipore. Antibodies against p-MCM2 (ab109133, ab133243) and MCM2 (ab4461) were purchased from Abcam. Antibody against $\beta$-actin (66009-1-Ig) was purchased from Proteintech. Antibodies against p-ATR (Thr1989) (30632) and p-CHK1 (Ser345) (2348 T) were purchased from Cell Signaling Technology.

\section{Pooled CRISPR screen and data processing}

For the design of the kinome CRISPR library, 5971 gRNAs targeting 504 human kinases, 10 essential genes, and 50 non-targeting gRNAs were selected (Additional file 1: Table S1). Oligos with gRNA sequences flanked by adapters were ordered from CustomArray (Bothell, Washington, USA) and cloned as a pool by GIBSON assembly in LentiCRISPRv2.1 [30]. The kinome CRISPR library was introduced into MHCC97H cells by lentiviral transduction. Cells stably expressing gRNA were cultured for 14 days. The abundance of each gRNA 
in the pooled samples was determined by Illumina deep sequencing. Single-end reads were trimmed and qualityfiltered and then matched against sgRNA sequences from the kinome CRISPR library. Subsequently, read counts of sgRNAs were normalized against total read counts across all samples. For each sgRNA, the fold change value for enrichment was calculated between the T14 (cultured for 14 days) group and T0 group.

\section{Protein lysate preparation and western blots}

Cells were washed with phosphate-buffered saline (PBS) and lysed with RIPA buffer supplemented with Complete Protease Inhibitor (Roche) and Phosphatase Inhibitor Cocktails II and III (Sigma). All lysates were freshly prepared and processed with Novex NuPAGE Gel Electrophoresis Systems (Invitrogen).

\section{Cell proliferation assays}

Cells were seeded into six-well plates $\left(1.5-3 \times 10^{4}\right.$ cells per well) and cultured in the presence of drugs as indicated. For each cell line, cells cultured at different conditions were fixed with $4 \%$ paraformaldehyde (in PBS) at the same time. Afterwards, cells were stained with $0.1 \%$ crystal violet (in water).

\section{Incucyte cell proliferation assay and apoptosis assay}

Cells were cultured and seeded into 96-well plates at a density of 1000-1500 cells per well. Twenty-four hours later, drugs were added at indicated concentrations. Cells were imaged every $4 \mathrm{~h}$ in IncuCyte ZOOM (Essen Bioscience). Phase-contrast images were collected and analyzed to detect cell proliferation based on cell confluence. For cell apoptosis, caspase-3/7 green apoptosis assay reagent was also added to culture medium and cell apoptosis was analyzed based on green fluorescent staining of apoptotic cells. For each condition, at least three replicates (50 cells/field) were analyzed.

\section{RNA sequencing and data processing}

$\mathrm{PLC} / \mathrm{PRF} / 5$ cells were cultured in the presence or absence of $10 \mu \mathrm{M}$ XL413 for $96 \mathrm{~h}$. Total RNA was extracted using the Trizol reagent (Invitrogen), and the library was prepared using TruSeq RNA sample prep kit according to the manufacturer's protocol (Illumina). For data analysis, raw sequencing reads were mapped to the human genome (GRCh38) using STAR (version 2.4.2 g1) [31]. Then, gene-level read counts were generated using featureCounts from the subRead package with default settings [32].

\section{Neutral comet assay}

Cells were harvested and embedded in 1\% lowgelling-temperature agarose (Sigma-Aldrich). Cell suspension was used to make gels onto comet assay slides (Trevigen). Cells in the agarose gels were lysed at $37^{\circ} \mathrm{C}$ in lysis buffer ( $2 \%$ sarkosyl, $0.5 \mathrm{M} \mathrm{Na}_{2}$ EDTA, and $0.5 \mathrm{mg} / \mathrm{ml}$ Proteinase K) overnight. Subsequently, slides were washed three times for $30 \mathrm{~min}$ at room temperature in electrophoresis buffer $(90 \mathrm{mM}$ Tris$\mathrm{HCl} \mathrm{pH}=8.5,90 \mathrm{mM}$ Boric Acid and $2 \mathrm{mM}$ $\mathrm{Na}_{2} \mathrm{EDTA}$ ). Electrophoresis was performed for $25 \mathrm{~min}$ at $20 \mathrm{~V}$ in electrophoresis buffer. Afterwards, slides were washed once with MQ and DNA was stained using $2.5 \mu \mathrm{g} / \mathrm{ml}$ propidium iodide (PI) in MQ. Individual comets were imaged with Zeiss AxioObserver Z1 inverted microscope. Tail moment of individual comets was assessed using the CASP software. For each condition, at least 50 cells were analyzed.

\section{DNA fiber analysis}

Cells were pulse labeled with $25 \mu \mathrm{M}$ CldU followed by $250 \mu \mathrm{M}$ IdU for $20-45 \mathrm{~min}$ each. Labeled cells were trypsinized, lysed in spreading buffer $(200 \mathrm{mM}$ Tris-Hcl pH 7.4, $50 \mathrm{mM}$ EDTA, and 0.5\% SDS) and spread on microscope slide (Menzel-Gläser, Superfrost). DNA fibers were fixed on slides using 3:1 methanol: acidic acid. Slides were treated with $2.5 \mathrm{M}$ $\mathrm{HCl}$ for $1 \mathrm{~h}$ and $15 \mathrm{~min}$ to denature DNA followed by $1 \mathrm{~h}$ incubation in blocking buffer (PBS, 1\% BSA, 0.1\% Tween20) to block background staining. For detection of CldU and IdU, slides were incubated for $1 \mathrm{~h}$ with rat-anti-Brdu (Clone BU1/75, Abcam; 1:500) and mouse-anti-BrdU (clone B44, Becton Diskinson; 1: 750), respectively. Subsequently, slides were fixed with 4\% paraformaldehyde for $10 \mathrm{~min}$ and incubated with Alexa 488-labeled goat-anti-mouse and Alexa 555labeled goat-anti-rat (Molecular probes; 1:500) for $1 \mathrm{~h}$ and $30 \mathrm{~min}$. DNA fibers were imaged with the Zeiss AxioObserver $\mathrm{Z} 1$ inverted microscope using a $63 \mathrm{x}$ objective equipped with a Hamamatsu ORCA AG Black and White CCD camera. Replication tracks lengths were analyzed using ImageJ software and the conversion factor $1 \mu \mathrm{m}=2.59 \mathrm{~kb}$ was used.

\section{Time-lapse live imaging}

To allow visualization of chromosomes, cells were transduced with a histone H2B-GFP (LV-GFP, Addgene plasmid\#25999). Cells were then plated $24 \mathrm{~h}$ before starting the microscope acquisition. XL413 $(10 \mu \mathrm{M})$, AZD6738 $(1.25 \mu \mathrm{M})$, and MK-8776 $(2.5 \mu \mathrm{M})$ were added in the medium $1 \mathrm{~h}$ before starting the movie. Cells were filmed over $96 \mathrm{~h}$ and pictures were taken every $8 \mathrm{~min}$. For each condition filmed, 5 different fields were selected. In each field, we randomly chose and followed cells entering in mitosis (nuclear envelope breakdown, NEBD, was used as indicator of mitotic division onset). 


\section{Xenografts}

Animals were housed in micro-isolator cages of dimensions $30.5 \mathrm{~cm} \times 19 \mathrm{~cm} \times 14 \mathrm{~cm}$, including a wire rack in the cage for holding food and a water bottle. Animals were housed on a 12-h light/dark cycle. A carbon dioxide (CO2) euthanasia method was applied to mice. All animals were manipulated and housed according to protocols approved by the Shanghai Medical Experimental Animal Care Commission and Shanghai Cancer Institute. Huh7 and MHCC97H cells $\left(1 \times 10^{7}\right.$ cells per mouse) were injected subcutaneously into the right posterior flanks of 6-week-old BALB/c nude mice (male, 8-9 mice per group). Tumor volume based on caliper measurements was calculated by the modified ellipsoidal formula: tumor volume $=1 / 2$ length $\times$ width $^{2}$. After tumor establishment, mice were randomly assigned to 5 days/ week treatment with vehicle, or AZD6738 $(50 \mathrm{mg} / \mathrm{kg}$, oral gavage). For combination treatment assay, PLC/ PRF $/ 5$ cells $\left(1 \times 10^{7}\right.$ cells per mouse $)$ were injected subcutaneously into the right posterior flanks of 6-week-old $\mathrm{BALB} / \mathrm{c}$ nude mice (male, 8 mice per group). Mice were randomly assigned to treatment 3 days/week with vehicle, XL413 (50 mg/kg, oral gavage), AZD6738 (50 mg/ $\mathrm{kg}$, oral gavage), or a drug combination in which each compound was administered at the same dose and schedule as single agent.

\section{Immunohistochemical staining}

Formalin-fixed paraffin-embedded samples were obtained from xenograft tumors and then probed with antibodies against $\gamma \mathrm{H} 2 \mathrm{AX}$ (\#9718, Cell Signaling Technology). Following incubation with the primary antibodies, positive cells were visualized using $\mathrm{DAB}+$ as a chromogen.

\section{Included public datasets}

Three clinical cohorts, including two RNAseq-based cohorts (CHCC and TCGA-LIHC) and one microarray-based cohort (GSE14520) were utilized for conducting clinical analysis [33-35]. Fragments per kilobase per million reads (FPKM) normalized transcriptome of $\mathrm{CHCC}$ cohort was downloaded from NODE (www.biosino.org/node). Gene expression data (raw counts) of LIHC cohort was obtained from TCGA website (portal.gdc.cancer.gov/repository) [34]. Expression data of GSE14520 cohort was assessed from the Gene Expression Omnibus (GEO) (www. ncbi.nlm.nih.gov/geo/) [36]. For sequencing data, raw counts, or FPKM normalized expression data were transformed into transcripts per kilobase million (TPM) values for subsequent analysis. For microarray data, robust multi-array average (RMA) method was used for normalization. Clinical data of samples from CHCC and GSE14520 cohorts were obtained from corresponding supplementary files [33, 35]; clinical data of TCGA cohort were downloaded from the TCGA Pan-Cancer Clinical Data Resource (TCGACDR) [37]. Drug sensitivity and molecular data of hundreds of cancer cell lines (CCLs) were obtained from the genomics of drug sensitivity in cancer (GDSC) (released October 2019, cancerrxgene.org) [38] and PRISM Repurposing dataset (19Q4, released December 2019, depmap.org/portal/prism/) [39]. The area under the dose-response curve (AUC) values in these datasets were used as a measure of drug sensitivity, and lower values indicate increased sensitivity to treatment. Gene dependency data was achieved from the dependency map (DepMap) portal (depmap. org/portal/) [40]. CERES score is taken as a measure of the gene dependency, and a lower CERES score indicates a higher likelihood that the gene is essential for cell growth and survival [40].

\section{Bioinformatics analysis}

Th replication stress gene set (c2.cp.reactome.v7.4) came from the Molecular Signatures Database (MSigDB), which included 37 replication stress-associated genes [41]. For Gene set enrichment analysis (GSEA), the fold change (FC) of each gene between subclasses was firstly calculated, and input genes were ranked in descending order according to the FC values. GSEA was then performed using GSEA software or clusterProfiler R package based on the replication stress gene set [42]. For single sample gene set enrichment analysis (ssGSEA), ssGSEA scores for each sample were computed through GSVA R package with default parameters based on the replication stress gene set [43]. ConsensusClusterPlus $\mathrm{R}$ package was utilized for k-means clustering [44]. Clustering was performed based on 37 replication stressassociated genes using Euclidean distance with 1000 iterations and $80 \%$ of sample resampling.

\section{Statistical analysis}

All the computational analyses and graphical visualization were performed with Prism (Graph Pad Prism v7) and R statistical software (Cran $\mathrm{R}$ project $\mathrm{R}$ program v3.6.0). Comparison of a continuous variable in two or more than two groups was performed using either a parametric test (Student's $t$ test or analysis of variance) or a nonparametric test (Wilcoxon rank-sum test or Kruskal-Wallis test). Correlation between two continuous variables was measured by either Pearson's $r$ correlation or Spearman's rank-order correlation. Survival analysis was carried out using Kaplan-Meier methods and the log-rank test was used to determine the statistical significance of differences. A two-tailed $P<0.05$ was considered significant unless indicated otherwise. 


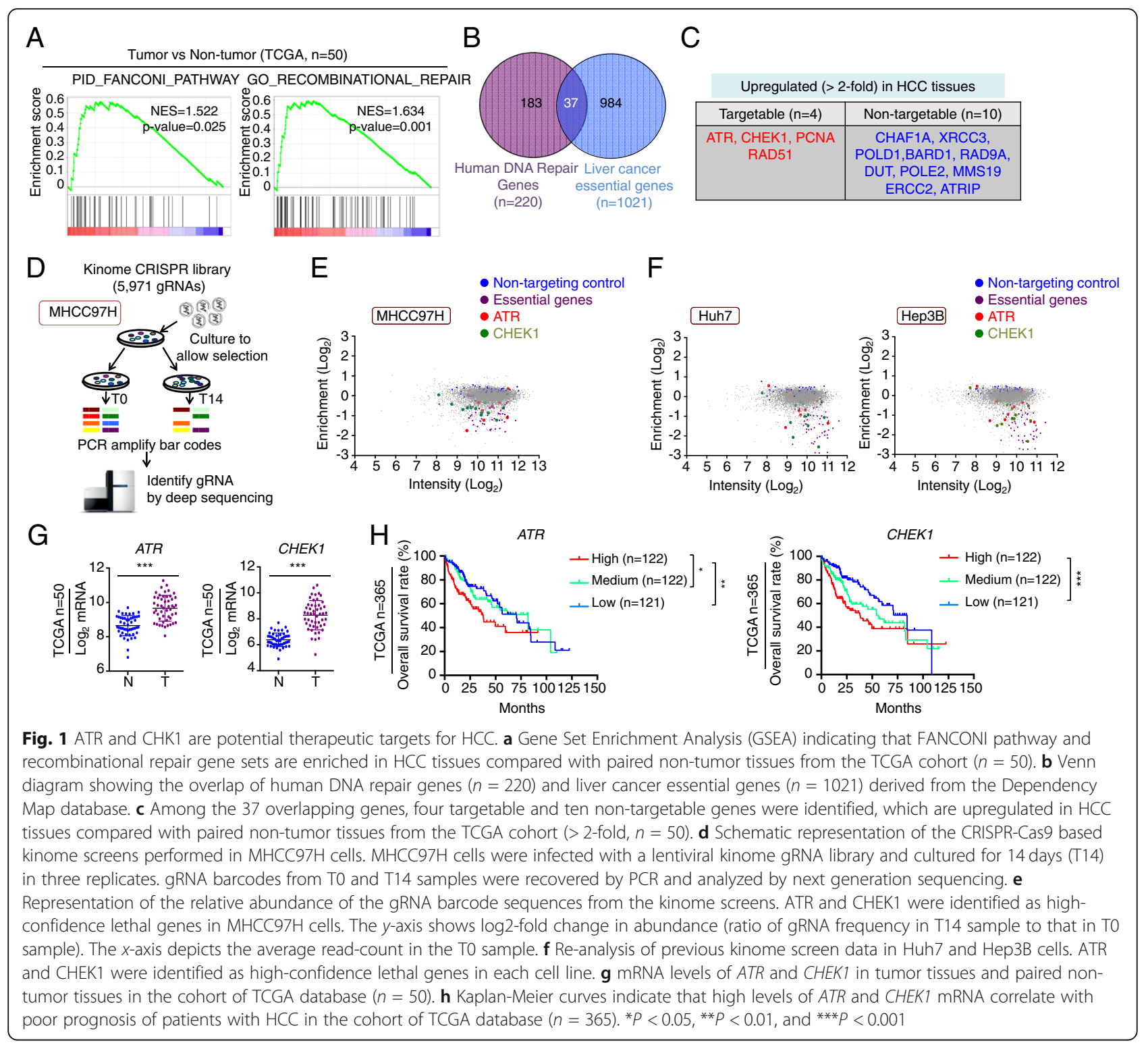

\section{Results}

\section{ATR and CHK1 are potential therapeutic targets for liver cancer}

To evaluate the activity of the DDR in HCC tissues, we first performed gene set enrichment analyses on RNAsequencing data of 50 paired tumor and non-tumor tissues from the TCGA database. Two DDR related gene sets, including FANCONI pathway and RECOMBINATIONAL REPAIR pathway, were significantly enriched in HCC tissues compared to non-tumor tissues (Fig. 1a). This suggests that targeting the DDR could be exploited as a potential treatment strategy for liver cancer. To explore genes involved in the DDR as potential drug targets in HCC therapy, we analyzed the gene dependencies of liver cancer cell lines $(n=22)$ in the DepMap public dataset. A total of 1021 genes were identified as liver cancer essential genes based on the probabilities of dependency, which are provided by DepMap public dataset (Fig. 1A and Additional file 2: Fig. S1a). A total of 220 human DNA repair genes described in previous studies [45-47] were used here (Fig. 1B and Additional file 3: Table S2). Among these 220 human DNA repair genes, 37 were liver cancer essential genes (Fig. 1B) and 14 of these 37 candidate genes were upregulated over 2-fold in primary liver cancer tissues according to the TCGA database (Fig. 1C). ATR and CHEK1, two master regulators of the DDR process with specific inhibitors already in clinical trials, were selected for further investigation (Additional file 2: Fig. S1a-b).

In parallel to these in silico studies, we performed a CRISPR-Cas9 genetic screen with a lentiviral guide RNA (gRNA) library that represents all human kinases in 
MHCC97H cells to find liver cancer-essential kinases (Fig. 1D). In agreement with the finding from the DepMap public dataset, we found that both $A T R$ and CHEK1 genes were required for the proliferation and survival of MHCC97H cells (Fig. 1E and Additional file 1: Table S1). We next re-analyzed our previous kinome screen data in Huh7 and Hep3B cells [25]. Here too, $A T R$ and CHEK1 were identified as high-confidence lethal genes in both cell lines (Fig. $1 \mathrm{~F}$ and Additional file 1: Table S1). Furthermore, the levels of ATR and CHEK1 mRNA were upregulated in tumor tissues compared to non-tumor tissues in the TCGA database $(n=50)$ and the GSE14520 cohort $(n=213)$ (Fig. $1 \mathrm{G}$ and
Additional file 2: Fig. S1c). Moreover, in a TCGA cohort of 365 patients with HCC stratified by tertile cut-off values, patients with the highest levels of $A T R$ or CHEK1 mRNA in their tumors exhibited the worst survival (Fig. 1H).

Next, we tested the potencies of ATR inhibitor AZD6738 and CHK1 inhibitor MK-8776 in liver cancer cell lines. We treated a panel of liver cancer cell lines with increasing concentrations of AZD6738 or MK-8776 for 10-14 days in colony formation assays. While the response to these compounds varied across cell lines, the activities of AZD6738 and MK-8776 on the panel of liver cancer cells were very similar (Fig. 2A).

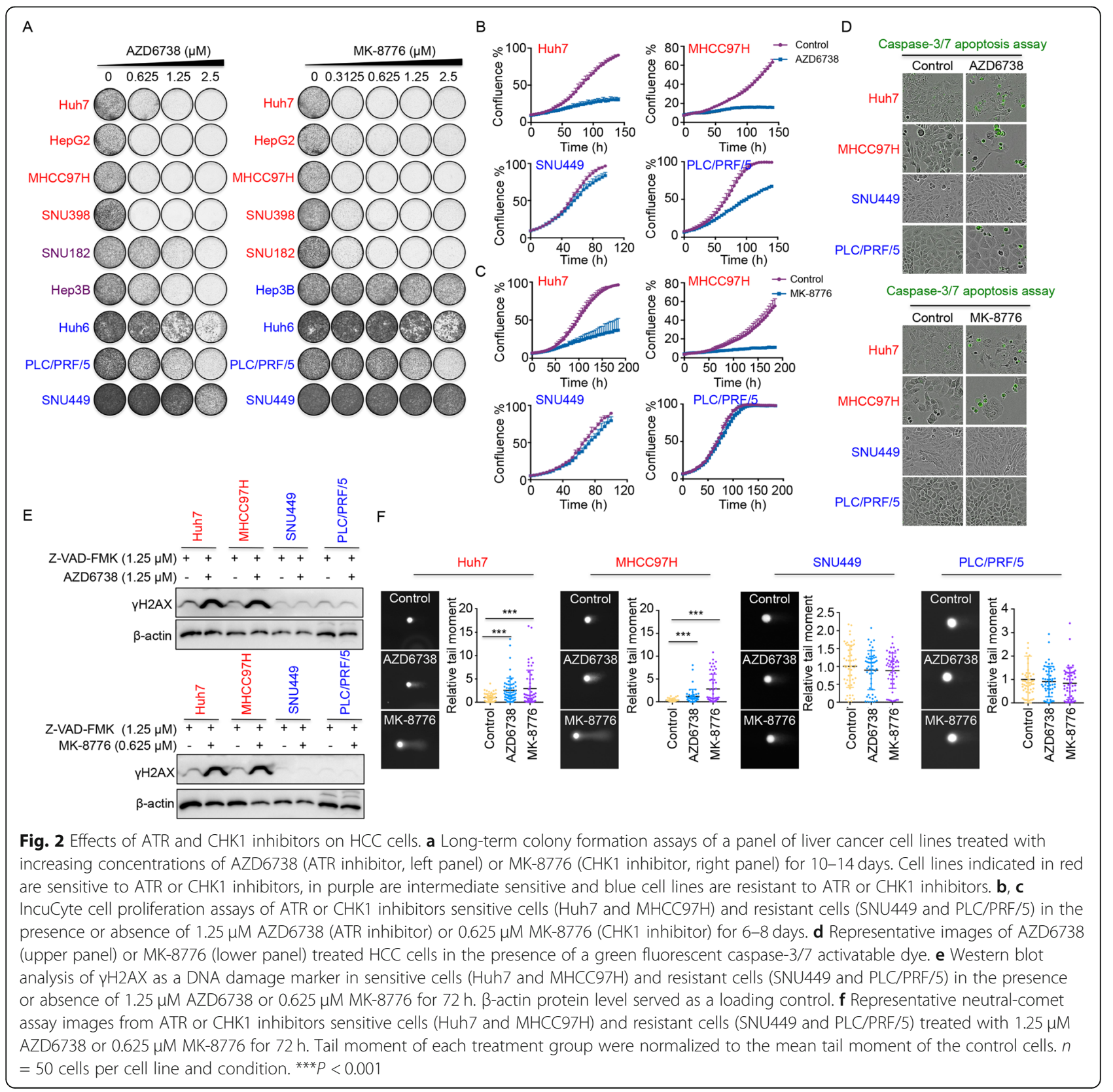


Functionally, liver cancer cell lines can be classified as either sensitive (Huh7, HepG2, MHCC97H, and SNU398) or resistant (Huh6, PLC/PRF/5, and SNU449) to ATR or CHK1 inhibitors (Fig. 2A). Comparable results were also obtained using IncuCyte short-term cell proliferation assays (Fig. 2B, C). ATR or CHK1 inhibition induced apoptosis in the sensitive cells (Huh7 and $\mathrm{MHCC} 97 \mathrm{H})$, as indicated by the caspase- $3 / 7$ apoptosis assay, but not in the resistant cell lines (SNU449 and PLC/PRF/5) (Fig. 2D and Additional file 2: Fig. S2). To further address the selective effects of AZD6738 or MK8776 in sensitive cell lines, we assessed $\gamma \mathrm{H} 2 \mathrm{AX}$ protein levels, a marker for DNA damage, following treatment with AZD6738 or MK-8776. To ensure that $\gamma \mathrm{H} 2 \mathrm{AX}$ comes from accumulated DNA damage but not increased apoptosis, we added a caspase inhibitor Z-VADFMK in the medium. After treatment with AZD6738 or MK-8776, the level of $\gamma \mathrm{H} 2 \mathrm{AX}$ was clearly induced in the two sensitive liver cancer cells (Huh7 and MHCC97H) as compared to the resistant cell lines (SNU449 and PLC/PRF/5) (Fig. 2E). Comparable results were also obtained using neutral comet assays (Fig. 2F). In addition, we also investigated whether ATR and CHEK1 expression could be potential biomarkers of drug response to ATR or CHK1 inhibitors. We conducted correlation analyses between expression of ATR/CHEK1 and drug response of AZD6738 (the drug response data of MK8776 was absent in public datasets). The results suggested that both $A T R$ and CHEK1 expressions were correlated with sensitivities to ATR inhibition by AZD6738. However, only the expression of CHEK1 had a significant correlation with drug response of AZD6738 $(P=$ 0.014 ), while $A T R$ did not have a statistical significance (Additional file 2: Fig. S1d). This result suggests that using a single target gene (i.e. ATR or CHEK1) for predicting the drug response of the corresponding inhibitor may not be the most appropriate option in this case.

Together, these findings suggest that ATR and CHK1 could represent potential therapeutic targets for liver cancer. However, effective biomarkers of drug response and powerful drug combination strategies are still required for resistant cells.

\section{CDC7 inhibitor induces DNA replication stress in HCC cells}

To discover potential biomarkers of response to ATR and CHK1 inhibitors, we performed integrated bioinformatics analyses using gene expression and drug response data from the GDSC and PRISM databases [38, 39]. Enrichment of the replication stress signature was estimated by ssGSEA method based on 37 replication stress-related genes (see the "Methods" section). We found that the abundance of the replication stress signature was significantly associated with the sensitivity to the ATR inhibitor AZD6738 (Fig. 3A, left panel). A similar trend was observed for the relationship between the replication stress signature and the CHK1 inhibitor LY2606368, albeit that this was not significant (LY2606368, Fig. 3A, right panel). Importantly, when we analyzed the pan-cancer cell lines, although the correlations were still statistically significant, the correlation coefficients were relatively low $(<0.15$ in AZD6738 and LY2606368, Additional file 2: Fig. S3), indicating that this correlation might be context dependent. Western blot analysis of $\gamma \mathrm{H} 2 \mathrm{AX}$, a marker for both DNA damage and DNA replication stress $[18,48]$, indicated that the basal levels of $\gamma \mathrm{H} 2 \mathrm{AX}$ were clearly higher in four sensitive liver cancer cell lines compared to three cell lines resistant to ATR or CHK1 inhibitors (Fig. 3B).

CDC7 kinase plays important roles in the maintenance of DNA damage response and DNA replication forks and has attracted attention as a target to inducing replication stress [28]. Gene set enrichment analyses of RNA-sequencing data from PLC/PRF/5 cells treated with XL413 showed the enrichment of a gene set related to DNA replication stress (GSE183751, Fig. 3C). To evaluate the effects of the CDC7 inhibitor on origin firing and replication fork speed, we performed DNA fiber assays. PLC/PRF/5 cells treated with XL413 exhibited decreased origin firing as compared to control cells. In contrast, treatment with XL413 led to increased DNA replication fork progression, probably as a compensation for the reduction of origin firing (Fig. 3D-F), which is consistent with previous reports of several different CDC7 inhibitors $[28,49]$. When we inhibited CDC7 in liver cancer cells with the CDC7 inhibitor XL413, we observed strong suppression of its downstream target p-MCM2 at XL413 concentrations of $5 \mu \mathrm{M}$ to $10 \mu \mathrm{M}$ (Fig. 3G). Western blot analysis revealed that treatment with XL413 caused accumulation of cyclin B1, suggesting an increase in the number of S-G2 phase arrested cells (Fig. 3G). The detection of phosphorylation of ATR and CHK1 by western blot indicated activation of ATR-CHK1 signaling upon CDC7 inhibition (Fig. 3H), further suggesting the potential dependency of ATR-CHK1 signaling for cell survival upon CDC7 inhibitor treatment.

The activation of DNA replication stress by CDC7 inhibition prompted us to study the combination effect of CDC7 and ATR inhibition on DNA damage induction. PLC/PRF/5 and SNU449 cells, which are resistant to ATR and CHK1 inhibitors, were incubated with XL413, AZD6738, and MK-8776 or the indicated combinations for $72 \mathrm{~h}$, after which DNA damage induction was measured. The caspase inhibitor Z-VAD-FMK was also added into the medium to exclude apoptosis-associated $\gamma \mathrm{H} 2 \mathrm{AX}$. We observed synergistic induction of DNA 


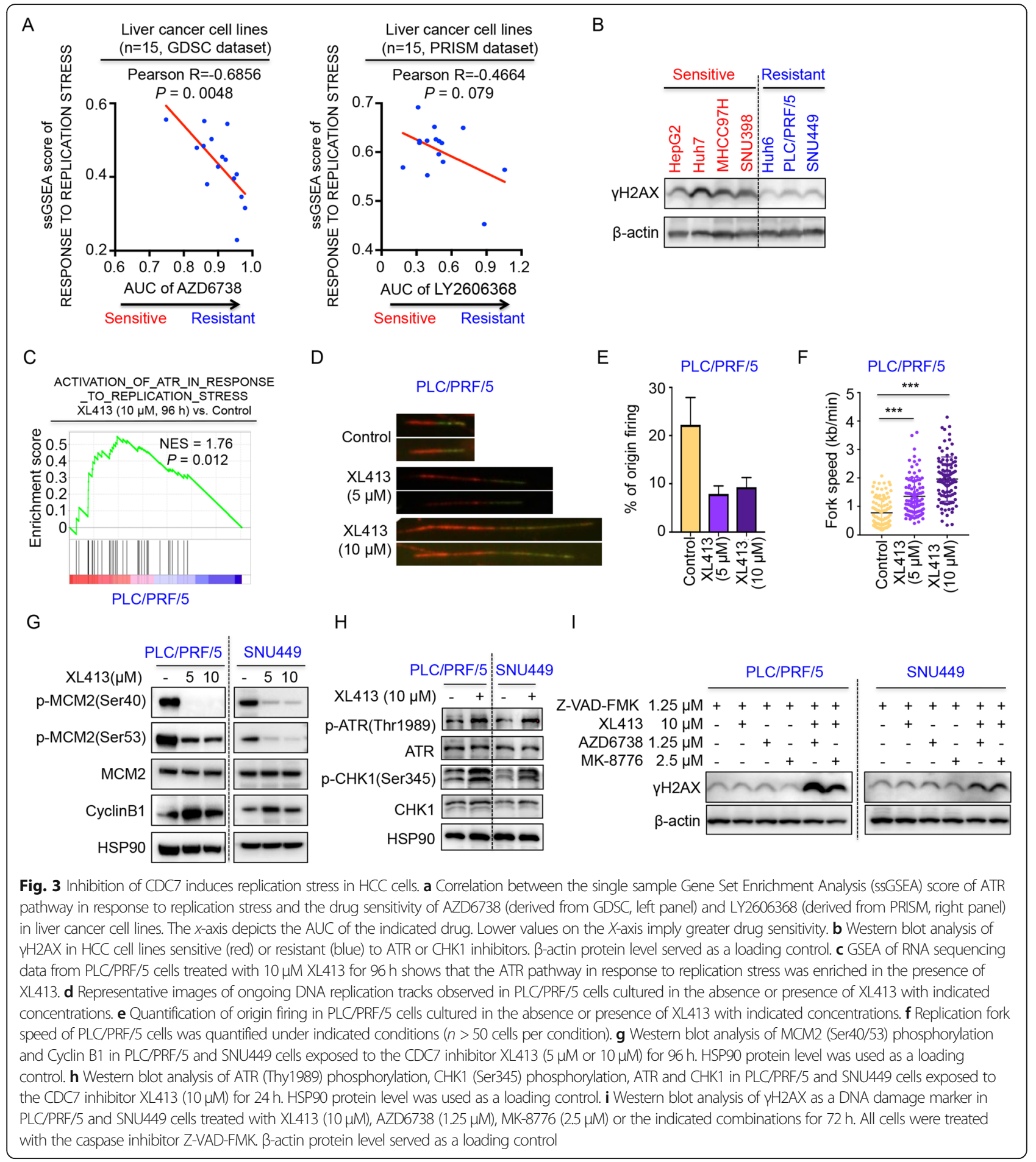

damage by CDC7 and ATR-CHK1 inhibition in both cell lines as demonstrated by immunoblot of $\gamma \mathrm{H} 2 \mathrm{AX}$ (Fig. 3I). These findings indicate that DNA replication stress signature could be an effective biomarker for drug response of ATR and CHK1 inhibitors for liver cancer, which can also be exploited for synergistic induction of DNA damage.
CDC7 inhibition is synergistic with ATR and CHK1 inhibitors in liver cancer cells

The strong synergistic induction of DNA damage by the combination treatment of $\mathrm{CDC} 7$ inhibitor with ATR or CHK1 inhibitors led us to explore the synthetic lethal effects of these drug combinations on cell killing. We observed synergistic effects on cell proliferation by XL413 
and ATR or CHK1 inhibition (AZD6738 or MK-8776) in all three ATR or CHK1 inhibitor resistant liver cancer cell lines (Fig. 4A-C). Strong synergistic induction of apoptosis was also observed in PLC/PRF/5 and SNU449 cells when XL413 was combined with AZD6738 or MK8776 as indicated by the IncuCyte caspase-3/7 apoptosis assay (Fig. 4D, E). To further validate the synthetic lethal effects of CDC7 and ATR-CHK1 inhibition, we studied combinations of different CDC7 inhibitors (LY3177833 and TAK-931) and another ATR inhibitor (BAY1895344) or CHK1 inhibitor (LY2606368) in HCC cell lines (Additional file 2: Fig. S4a-d and Additional file 2: Fig. S5a-d). All these different combinations of CDC7 inhibitors with ATR or CHK1 inhibitors showed striking synergistic responses on proliferation inhibition and apoptosis induction in PLC/PRF/5 and SNU449 cells (Additional file 2: Fig. S4a-d and Additional file 2: Figure S5a-d). To further confirm that induction of DNA replication stress can sensitize cells to ATR or CHK1 inhibitors, we treated cells with cisplatin, a commonly used chemotherapy drug, which induces strong DNA replication stress [50]. Similar to CDC7 inhibition, treatment with cisplatin synthesizes liver cancer cells to AZD6738, further supporting the relation between DNA replication stress and the sensitivity of ATR or CHK1 inhibitors (Additional file 2: Fig. S6a-e).

Next, we used live cell microscopy to monitor individual cell fates to understand the cell cycle response of liver cancer cells to drug treatment. PLC/PRF/5 and SNU449 cells stably expressing GFP-histone 2B enabled us to track the fates of individual cells and their progenies (Fig. 5A, B). PLC/PRF/5 and SNU449 cells treated with a combination of $\mathrm{CDC7}$ and ATR or CHK1 inhibitors showed significant elevated mitosis duration by comparison to mono-treatment of $\mathrm{CDC} 7$ inhibitor or ATR-CHK1 inhibition (Fig. 5C). Furthermore, upon the combination treatment, cell death was also obviously increased in both mitosis and interphase (Fig. 5D). The synergy between ATR-CHK1 inhibition and CDC7 inhibition possibly derives from problems in mitosis (elevated mitosis length and abnormal chromosome segregation) inducing mitotic catastrophe.

\section{CDC7 inhibition sensitizes HCC cells towards AZD6738 treatment in vivo}

To assess whether our in vitro findings can be recapitulated in vivo, we generated Huh7, MHCC97H, and PLC/ PRF/5 xenografts. Upon tumor establishment, Huh7 and MHCC97H xenografts were treated with either vehicle or AZD6738 for 12 days and 18 days, respectively. AZD6738 treatment significantly impaired tumor growth of Huh7 and MHCC97H xenografts (Fig. 6A). AZD6738-treated tumors showed increased $\gamma \mathrm{H} 2 \mathrm{AX}$ positive cells as compared to tumors treated with vehicle, which indicates that inhibition of ATR induces DNA damage in Huh7 and MHCC97H xenografts
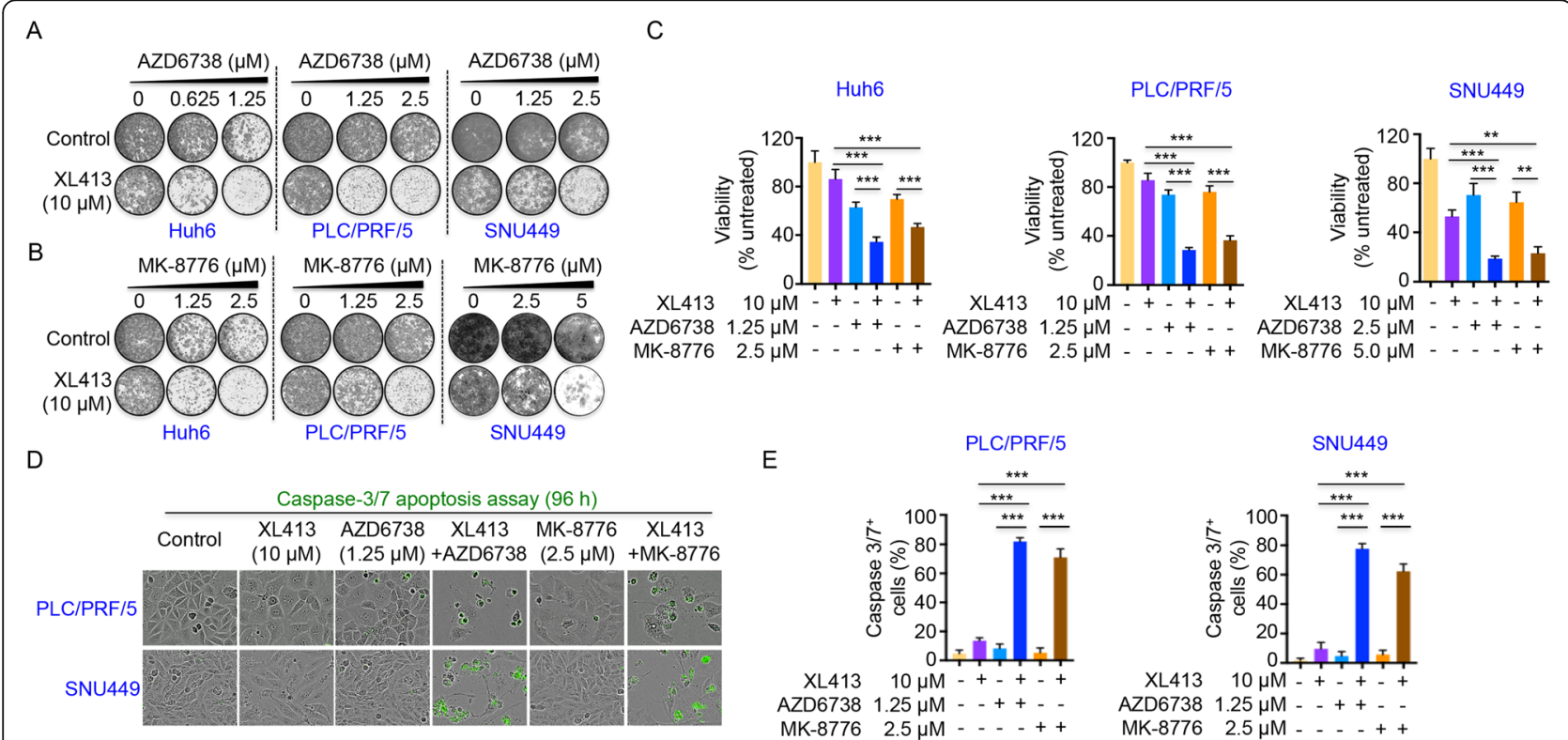

Fig. 4 CDC7 inhibitor synergies with AZD6738 or MK-8776 in HCC cells. a, b Short-term colony formation assays showing synergistic response to XL413 $(10 \mu \mathrm{M})$ combined with AZD6738 or MK-8776 in three HCC cell lines (resistant to ATR or CHK1 inhibitors: Huh6, PLC/PRF/5 and SNU449) after 4-5 days treatment. c Quantification of CellTiter-Blue viability assays of Huh6, PLC/PRF/5, and SNU449 cells treated with XL413, AZD6738, MK-8776 or the combination at the indicated concentrations. d, e Representative images of PLC/PRF/5 and SNU449 cells treated with XL413, AZD6738, MK-8776 or the indicated combinations for $96 \mathrm{~h}$ in the presence of a green fluorescent caspase-3/7 activatable dye. The proportion of cells containing caspase-3/7 staining is shown 


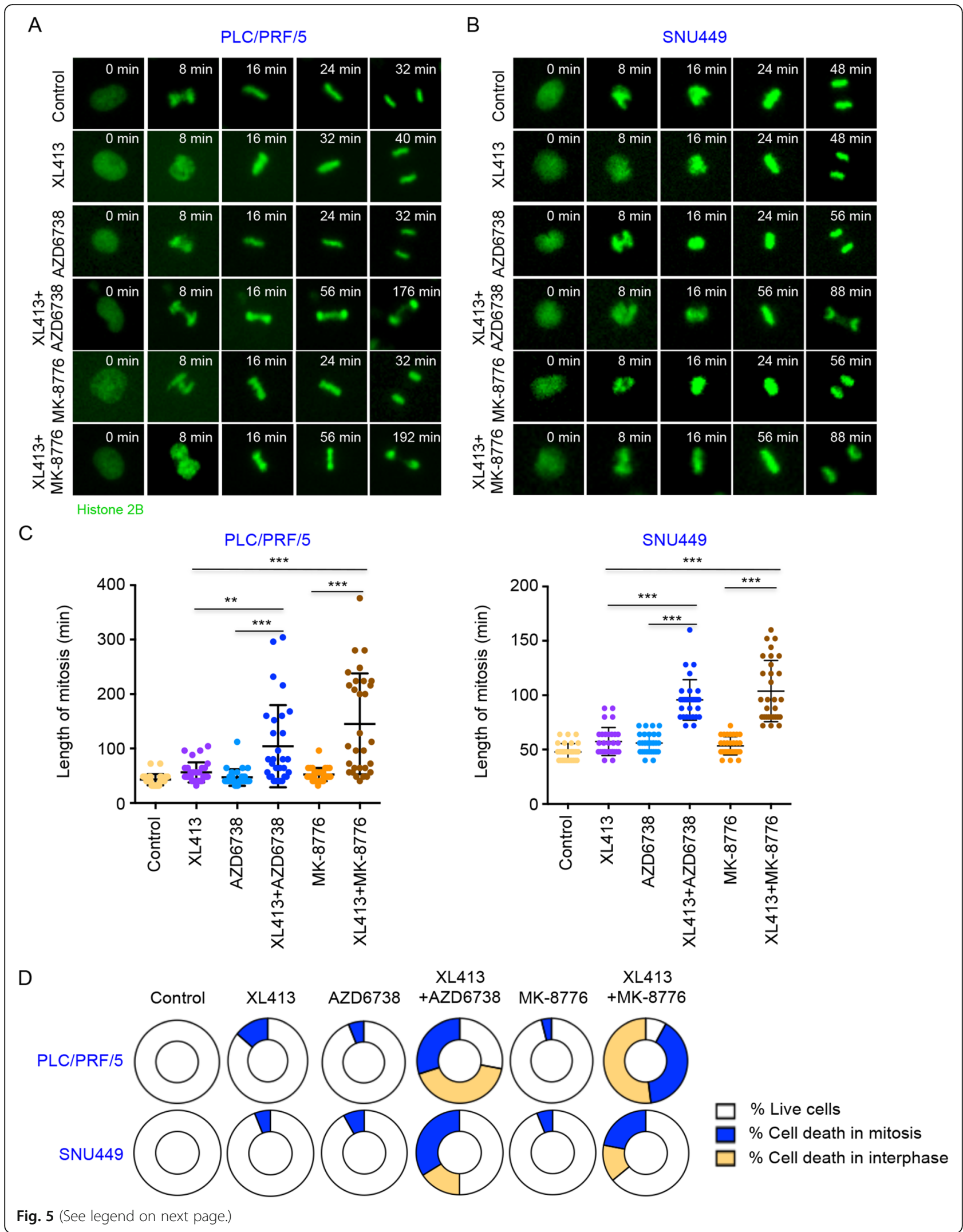


(See figure on previous page.)

Fig. 5 Combined CDC7 and ATR-CHK1 inhibition leads to defective cell cycle of HCC cells. a, b Representative live cell images of PLC/PRF/5 and

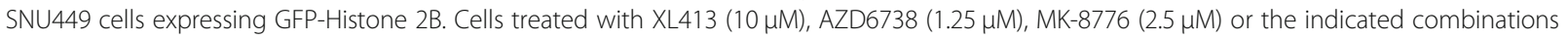
were monitored by time-lapse microscopy. c Quantification of mitosis duration based on time-lapse microscopy analysis $(n>30$ cells per cell line

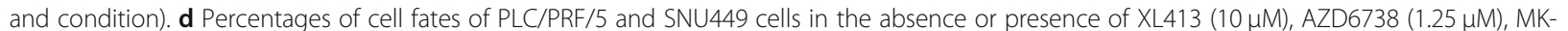
$8776(2.5 \mu \mathrm{M})$ or the indicated combination were analyzed using time-lapse microscopy $\left(n=50\right.$ cells per group). ${ }^{* *} P<0.01$ and ${ }^{* * *} P<0.001$

(Fig. 6B). Consistent with in vitro results, mice bearing $\mathrm{PLC} / \mathrm{PRF} / 5$ xenografts that received AZD6738 monotherapy showed a modest reduction in tumor volume, whereas treatment with XL413 combined with AZD6738 significantly reduced tumor burden compared to monotherapy (Fig. 6C). We observed that ATR or CDC7 inhibition led to increased DNA damage in tumor cells, as measured by $\gamma \mathrm{H} 2 \mathrm{AX}$ staining. Importantly, combination treatment synergistically induced far stronger DNA damage in tumor tissues (Fig. 6D). In addition,

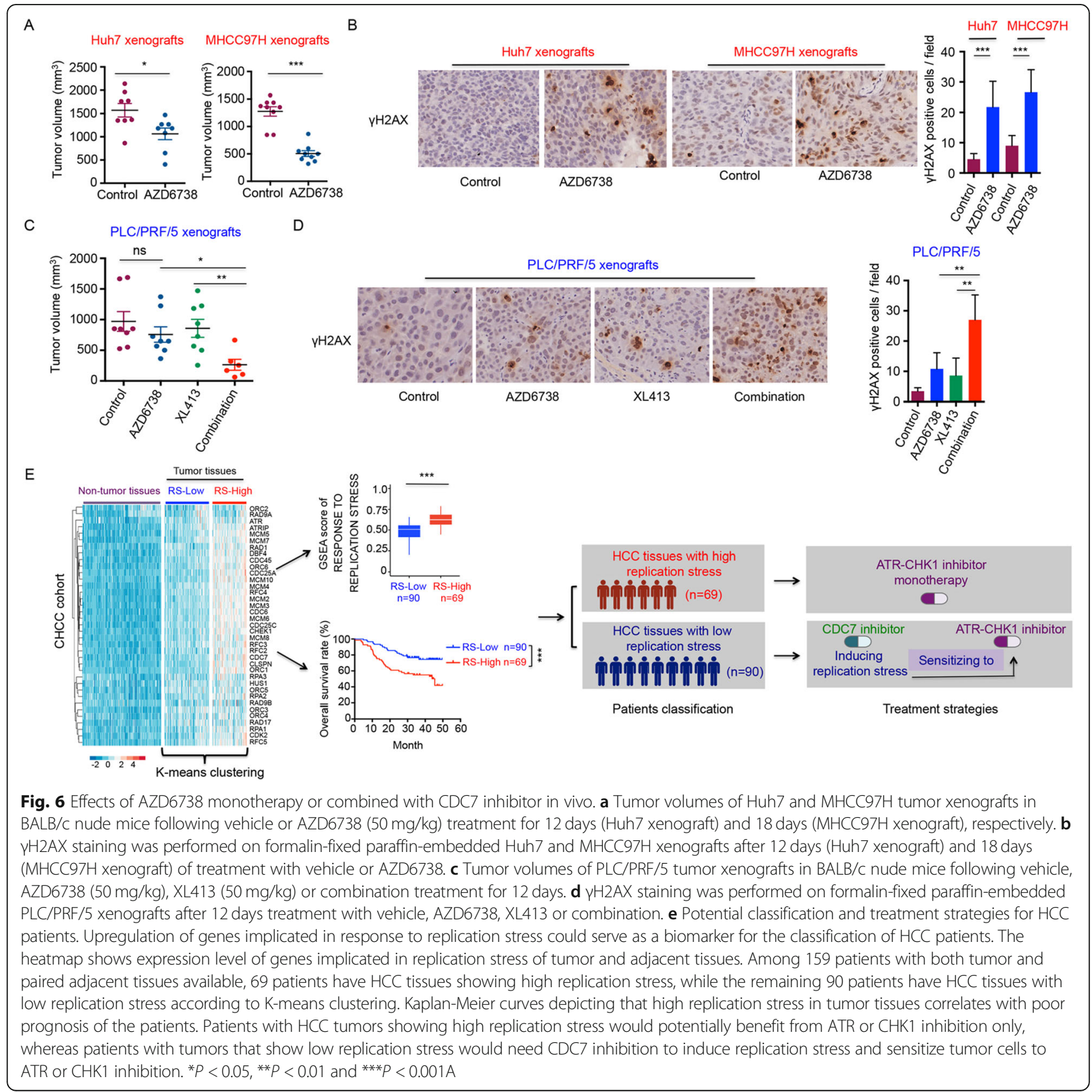


some side effects, such as weight loss and intestinal impairment, have been observed in mice treated with combination of $\mathrm{CDC7}$ plus ATR inhibitors.

\section{Potential classification and treatment strategy for HCC patients}

To investigate whether differences in replication stress levels are also present in clinical samples, we reanalyzed our previous RNA sequencing data, consisting of paired tumor and nontumor tissues from 159 primary HCC patients who underwent curative resection between 2010 and 2014 at Zhongshan Hospital (CHCC cohort) [35]. Based on a set of 37 curated genes involved in response to replication stress, we performed $\mathrm{K}$-means clustering and thereby divided 159 tumors into two subgroups having distinct levels of replication stress-associated gene expression (Fig. 6E). GSEA-based enrichment scores of the replication stress response signature calculated according to the differential fold change values between paired tumor and non-tumor tissues also showed a significant difference between these two subgroups, further supporting the presence of differences in replication stress among clinical samples (Fig. 6E). Notably, survival analysis indicated that tumors of patients having higher levels of transcription of replication stress signature genes experienced worse prognosis, extending the potential utility of this signature from a predictive biomarker to a predictive/prognostic biomarker (Fig. 6E). All above results have also been validated using an external cohort GSE14520 (Additional file 2: Fig. S7a). We also investigated the relationship between replication stress signature and clinical features. Therefore, we used the CHCC cohort, since it has the most comprehensive clinical information. We observed that a high replication stress signature was closely related to the presence of tumor thrombus, high AFP level, advanced BCLC stage, and advanced TNM stage (Additional file 2: Fig. S7b).

According to the findings reported above, a potential treatment strategy for HCC can be envisioned. Patients with a high replication stress gene signature may benefit from monotherapies of ATR or CHK1 inhibitors, while a combination strategy that includes $\mathrm{CDC7}$ inhibition may be required for patients with tumors having low levels of replication stress (Fig. 6E).

\section{Discussion}

In this study, through integrating the data from genomewide CRISPR screening and analyses of clinical cohorts, we identified ATR and CHK1 as potential therapeutic targets for treatment of HCC. Exploiting CRISPR functional screens to investigate the vulnerabilities of cancer cells can uncover new therapeutic opportunities. Previous large-scale CRISPR screening data from the cancer dependency map portal (depmap.org) provided a treasure trove which has not been explored fully yet. Utilizing this resource, some studies have obtained encouraging findings. For instance, the WRN helicase was identified as a vulnerability of microsatellite unstable cancers [51, 52]. In MYCN-amplified neuroblastoma, 147 selective candidate gene dependencies were identified, providing potential therapeutic insight for this difficult to treat childhood cancers [53]. Interestingly, although CRISPR screening data from DepMap as well as our own screens indicate that all liver cancer cell lines have a dependency on ATR and CHK1, only a subset of these cell lines were responded to ATR or CHK1 inhibitors, presumably due to the discrepancy between complete CRISPR gene knockout and partial small-molecule protein inhibition [54]. Based on this finding, further investigations were undertaken to identify biomarkers of response to these drugs and to identify drug combination strategies to overcome intrinsic resistance to ATR or CHK1 inhibitors.

Almost all currently approved therapies for HCC are based on the "one fits all" principle and consequently fail to deliver significant clinical benefit in an unselected patient population. Thus, for any drug, it is important to identify suitable predictive biomarkers for patient selection. Previously, several studies have reported that multigene transcriptome signatures exhibited good performance for predicting clinical efficacy of chemotherapy or targeted therapy $[55,56]$. The MammaPrint ${ }^{\mathrm{Tm}} 70$-gene signatures and OncotypeDx tests are examples of clinically used gene signatures for the prediction of chemotherapy benefit in early breast cancer [57, 58]. In our study, a gene signature of replication stress was identified, which could not only predict the efficacy of ATR or CHK1 inhibitors but also could be used to identify patients that may benefit from combination therapy with a CDC7 inhibitor.

Our data indicate that the levels of replication stress determine the sensitivity of liver cancer cells to ATR or CHK1 inhibitors. Consistent with this notion, we found that this replication stress signature was also enriched in $\mathrm{HCC}$ cells in the presence of $\mathrm{CDC7}$ inhibitor and that CDC7 inhibition sensitizes to ATR and CHK1 inhibition. Previous studies reported that the ATR-CHK1 pathway was required to cope with the high levels of replication stress in cancer cells [12, 29, 59]. Mechanistically, we show that dual CDC7 and ATR or CDC7 and CHK1 inhibition results in an increase in time spent in mitosis and mitotic catastrophe. Generally, replication stress results in stalling of replication forks and is followed by accumulation of single-stranded DNA (ssDNA), which then activates ATR signaling pathway and thus results in phosphorylation of the CHK1 kinase. In our study, XL413 treatment did not completely inhibit fork firing. The small number of active forks was supported by the increased speed of fork progression as a compensation. 
The activity of the ATR-CHK1 pathway has crucial roles in stabilizing stalled forks and promoting recovery, as well as activating cell cycle checkpoints to prevent cells with un-replicated DNA entering mitosis [60]. In the absence of ATR and CHK1, stalled forks can collapse, and the formation of DNA double-strand breaks (DSBs) will ensue. When entering mitosis, these defective cells are eliminated by mitotic catastrophe $[59,61]$. Therefore, intact ATR-CHK1 response is required for the survival of cells experiencing high levels of replication stress, and this pathway can thus be exploited as an attractive therapeutic target for selective elimination of malignant cells.

HCC is a highly aggressive cancer type that lacks effective therapeutics. The most frequent mutations in HCC are currently undruggable, which limits the development of targeted therapies for HCC. It is therefore urgent to develop novel targeted therapies for HCC. Even though a number of ATR and CHK1 inhibitors have been developed and tested as potential anti-tumor agents, the efforts are mainly focused on tumor types exhibiting high levels of replication stress, such as melanoma, pancreatic cancer, and neuroblastoma [14, 62, 63]. In the field of liver cancer, despite some preliminary findings, the therapeutic roles of ATR or CHK1 inhibitors remain to be explored [21, 23]. In this study, we have uncovered potential therapeutic uses of ATR or $\mathrm{CHK} 1$ inhibitors in $\mathrm{HCC}$ as well as the mechanism of intrinsic resistance to ATR-CHK1 inhibition. The identification of replication stress as a biomarker of response to ATR or CHK1 inhibitors allows selection of patients for monotherapies. Moreover, for patients with low replication stress tumors, addition of $\mathrm{CDC7}$ inhibitor will possibly result in increased replication stress and thereby sensitize tumor cells to ATR or CHK1 inhibitors. With both ATR and CDC7 inhibitors now in clinical trials, our work provides a mechanistic underpinning for their combination [12, 24]. However, some issues still need to be solved. One of the most important problems is toxicity. During our in vivo experiments, we observed that combination of $\mathrm{CDC7}$ and ATR inhibitors caused side effects including weight loss and intestinal impairment in mice. More work is needed to investigate how to best combine these drugs. Sequential or alternating dosing schedules could for instance be used to reduce the toxicity of drugs. That sequential therapies of otherwise toxic drug combinations can be effective was recently shown for the combination of PARP and WEE1 inhibitors [64].

\section{Conclusions}

Our data highlights the potential of targeting ATRCHK1 signaling, either alone or in combination with CDC7 inhibition, for the treatment of liver cancer based on the level of replication stress. Our results demonstrate the feasibility of personalized therapeutic opportunities in liver cancer.

\section{Supplementary Information}

The online version contains supplementary material available at https://doi. org/10.1186/s13073-021-00981-0.

Additional file 1: Table S1. Kinome screen data for HCC cells.

Additional file 2: Fig S1. ATR and CHK1 are potential therapeutic targets for HCC. Fig S2. Effects of ATR and CHK1 inhibitors on apoptosis induction of HCC cells. Fig S3. Relationship between the replication stress response signature and drug response. Fig S4. CDC7 inhibitors synergies with ATR or CHK1 inhibition in HCC cells. Fig S5. CDC7 inhibition synergies with ATR or CHK1 inhibitors in HCC cells. Fig S6. Cisplatin synergies with ATR inhibitor in HCC cells. Fig S7. Clinical association of replication stress signature.

Additional file 3: Table S2. List of 220 DNA repair genes.

Additional file 4. Original blots for all western blots results.

\section{Acknowledgements}

We thank the facilities of Netherlands Cancer Institute: Sequencing and Bioimaging.

\section{Authors' contributions}

C.W. and R.B. conceived the idea and designed the study. C.W., R.B., and W.Q. supervised all research. Y.G., B.B., C.Y., C.W., and R.B. wrote the manuscript and prepared the figures. C.W., Y.G., B.B., and J.W. designed, performed, and analyzed in vitro experiments and interpreted the results of the xenografts model. J.W. and D.G. performed xenografts experiments. B.B. and F.G. designed, performed, and analyzed neutral comet assays and DNA fiber analysis. C.Y., C.L., Q.G., S.Z., X.M., and H.W. performed data analysis. R.L.B., H.t.R., X.Q., and C.S. provided advice for the project. All authors read and approved the final manuscript.

\section{Funding}

The research of the authors was funded by grants from the European Research Council (ERC 787925 to R.B.), the National Natural Science Foundation of China (81920108025, 81874229, 8207100977 and 82122047), Natural Science Foundation of Shanghai (21ZR1461200), Shanghai Municipal Education Commission-Gaofeng Clinical Medicine Grant Support (20181703), Shanghai Cancer Institute (ZZ2109RCPY, ZZ942113 and SB2006), the Development Fund for Shanghai Talents (2019081), National Facility for Translational Medicine (TMSK-2020-005 and TMSK-2021-129), National Science and Technology Key Project of China (2018ZX10732202-002-003), and Shanghai Municipal Science and Technology Major Project (20JC141100).

\section{Availability of data and materials}

Processed and raw sequencing data can be downloaded from NCBI GEO (GSE183751): https://www.ncbi.nlm.nih.gov/geo/query/acc.cgi?acc=GSE183 751 [65]. Original blots for all western blots shown are provided in Additional file 4

\section{Declarations}

Ethics approval and consent to participate

All animal work was approved by Shanghai Cancer Institute and performed according to relevant guidelines by the Shanghai Medical Experimental Animal Care Commission and Shanghai Cancer Institute.

Consent for publication

Not applicable.

\section{Competing interests}

The authors declare that they have no competing interests.

\section{Author details}

${ }^{1}$ State Key Laboratory of Oncogenes and Related Genes, Shanghai Cancer Institute \& Department of Liver Surgery, Renji Hospital, Shanghai Jiao Tong 
University School of Medicine, Shanghai, China. ${ }^{2}$ Division of Molecular Carcinogenesis, Oncode Institute, The Netherlands Cancer Institute, Plesmanlaan 121, 1066 CX Amsterdam, The Netherlands. ${ }^{3}$ Division of Tumour Biology and Immunology, The Netherlands Cancer Institute, Plesmanlaan 121, 1066 CX Amsterdam, The Netherlands. ${ }^{4}$ Liver Cancer Institute, Zhongshan Hospital, Fudan University, Key Laboratory of Carcinogenesis and Cancer Invasion, Ministry of Education, Shanghai, China. ${ }^{5}$ mmune Regulation in Cancer Group, German Cancer Research Center, D-69120 Heidelberg, Germany.

\section{Received: 25 February 2021 Accepted: 29 September 2021} Published online: 18 October 2021

\section{References}

1. Villanueva A. Hepatocellular carcinoma. N Engl J Med. 2019;380(15):1450-62.

2. Llovet JM, Ricci S, Mazzaferro V, Hilgard P, Gane E, Blanc JF, et al. Sorafenib in advanced hepatocellular carcinoma. N Engl J Med. 2008;359(4):378-90.

3. Kudo M, Finn RS, Qin S, Han KH, Ikeda K, Piscaglia F, et al. Lenvatinib versus sorafenib in first-line treatment of patients with unresectable hepatocellular carcinoma: a randomised phase 3 non-inferiority trial. Lancet. 2018; 391(10126):1163-73.

4. Bruix J, Qin S, Merle P, Granito A, Huang YH, Bodoky G, et al. Regorafenib for patients with hepatocellular carcinoma who progressed on sorafenib treatment (RESORCE): a randomised, double-blind, placebo-controlled, phase 3 trial. Lancet. 2017;389(10064):56-66.

5. Abou-Alfa GK, Meyer T, Cheng AL, El-Khoueiry AB, Rimassa L, Ryoo BY, et al. Cabozantinib in patients with advanced and progressing hepatocellular carcinoma. N Engl J Med. 2018;379(1):54-63.

6. Finn RS, Ryoo BY, Merle P, Kudo M, Bouattour M, Lim HY, et al. Pembrolizumab as second-line therapy in patients with advanced hepatocellular carcinoma in KEYNOTE-240: a randomized, double-blind, phase III trial. J Clin Oncol. 2020;38(3):193-202.

7. El-Khoueiry AB, Sangro B, Yau T, Crocenzi TS, Kudo M, Hsu C, et al. Nivolumab in patients with advanced hepatocellular carcinoma (CheckMate 040): an open-label, non-comparative, phase 1/2 dose escalation and expansion trial. Lancet. 2017;389(10088):2492-502.

8. Yau T, Park JW, Finn RS, Cheng AL, Mathurin P, Edeline J, et al. CheckMate 459: A randomized, multi-center phase III study of nivolumab (NIVO) vs sorafenib (SOR) as first-line (1L) treatment in patients (pts) with advanced hepatocellular carcinoma (aHCC). Ann Oncol. 2019;30:v874-5.

9. Faivre S, Rimassa L, Finn RS. Molecular therapies for HCC: looking outside the box. J Hepatol. 2020;72(2):342-52.

10. Llovet JM, Kelley RK, Villanueva A, Singal AG, Pikarsky E, Roayaie S, et al. Hepatocellular carcinoma. Nat Rev Dis Primers. 2021;7(1):6.

11. Finn RS, Qin S, Ikeda M, Galle PR, Ducreux M, Kim TY, et al. Atezolizumab plus bevacizumab in unresectable hepatocellular carcinoma. N Engl J Med. 2020;382(20):1894-905.

12. Lecona E, Fernandez-Capetillo O. Targeting ATR in cancer. Nat Rev Cancer. 2018;18(9):586-95.

13. Pilié $P G$, Tang C, Mills GB, Yap TA. State-of-the-art strategies for targeting the DNA damage response in cancer. Nat Rev Clin Oncol. 2019;16(2):81-104.

14. Walton Ml, Eve PD, Hayes A, Valenti MR, De Haven Brandon AK, Box G, et al. CCT244747 is a novel potent and selective CHK1 inhibitor with oral efficacy alone and in combination with genotoxic anticancer drugs. Clin Cancer Res. 2012;18(20):5650-61.

15. Walton MI, Eve PD, Hayes A, Valenti M, De Haven BA, Box G, et al. The preclinical pharmacology and therapeutic activity of the novel CHK1 inhibitor SAR-020106. Mol Cancer Ther. 2010;9(1):89-100.

16. Huntoon CJ, Flatten KS, Wahner Hendrickson AE, Huehls AM, Sutor SL, Kaufmann $\mathrm{SH}$, et al. ATR inhibition broadly sensitizes ovarian cancer cells to chemotherapy independent of BRCA status. Cancer Res. 2013;73(12):3683-91.

17. Murga M, Campaner S, Lopez-Contreras AJ, Toledo LI, Soria R, Montaña MF, et al. Exploiting oncogene-induced replicative stress for the selective killing of Myc-driven tumors. Nat Struct Mol Biol. 2011;18(12):1331-5.

18. Toledo LI, Murga M, Zur R, Soria R, Rodriguez A, Martinez S, et al. A cellbased screen identifies ATR inhibitors with synthetic lethal properties for cancer-associated mutations. Nat Struct Mol Biol. 2011;18(6):721-7.

19. Reaper PM, Griffiths MR, Long JM, Charrier JD, Maccormick S, Charlton PA, et al. Selective killing of ATM- or p53-deficient cancer cells through inhibition of ATR. Nat Chem Biol. 2011;7(7):428-30.
20. Gilad O, Nabet BY, Ragland RL, Schoppy DW, Smith KD, Durham AC, et al. Combining ATR suppression with oncogenic Ras synergistically increases genomic instability, causing synthetic lethality or tumorigenesis in a dosage-dependent manner. Cancer Res. 2010;70(23):9693-702.

21. Weng MT, Tung TH, Lee JH, Wei SC, Lin HL, Huang YJ, et al. Enhancer of rudimentary homolog regulates DNA damage response in hepatocellular carcinoma. Sci Rep. 2015;5:9357.

22. Hong J, Hu K, Yuan Y, Sang Y, Bu Q, Chen G, et al. CHK1 targets spleen tyrosine kinase $(L)$ for proteolysis in hepatocellular carcinoma. J Clin Invest. 2012;122(6):2165-75.

23. Sheng $H$, Huang $Y$, Xiao $Y$, Zhu Z, Shen M, Zhou P, et al. ATR inhibitor AZD6738 enhances the antitumor activity of radiotherapy and immune checkpoint inhibitors by potentiating the tumor immune microenvironment in hepatocellular carcinoma. J Immunother Cancer. 2020;8(1):e000340.

24. Montagnoli A, Moll J, Colotta F. Targeting cell division cycle 7 kinase: a new approach for cancer therapy. Clin Cancer Res. 2010;16(18):4503-8.

25. Wang C, Vegna S, Jin H, Benedict B, Lieftink C, Ramirez C, et al. Inducing and exploiting vulnerabilities for the treatment of liver cancer. Nature. 2019; 574(7777):268-72.

26. Shimizu T, Doi T, Kondo S, Takahashi H, Yamamoto N, Sheldon-Waniga E, et al. First-in-human phase 1 study of TAK-931, an oral cell division cycle 7 (CDC7) inhibitor, in patients (pts) with advanced solid tumors. J Clin Oncol. 2018;36(15_suppl):2506.

27. Gallagher PF, Coyle V, Evans TRJ, Plummer ER, Clive S, McGuigan L, et al. A CRUK first-in-human phase I trial of a CDC7 inhibitor, LY3143921 hydrate, in patients with advanced solid tumors. J Clin Oncol. 2019;37(15_suppl): TPS3167.

28. Iwai K, Nambu T, Dairiki R, Ohori M, Yu J, Burke K, et al. Molecular mechanism and potential target indication of TAK-931, a novel CDC7selective inhibitor. Sci Adv. 2019;5(5):eaav3660.

29. Rainey MD, Bennett D, O'Dea R, Zanchetta ME, Voisin M, Seoighe C, et al. ATR restrains DNA synthesis and mitotic catastrophe in response to CDC7 inhibition. Cell Rep. 2020;32(9):108096.

30. Evers B, Jastrzebski K, Heijmans JP, Grernrum W, Beijersbergen RL, Bernards R. CRISPR knockout screening outperforms shRNA and CRISPRi in identifying essential genes. Nat Biotechnol. 2016;34(6):631-3.

31. Dobin A, Davis CA, Schlesinger F, Drenkow J, Zaleski C, Jha S, et al. STAR: ultrafast universal RNA-seq aligner. Bioinformatics. 2013;29(1):15-21.

32. Liao Y, Smyth GK, Shi W. The Subread aligner: fast, accurate and scalable read mapping by seed-and-vote. Nucleic Acids Res. 2013;41(10):e108.

33. Roessler S, Long EL, Budhu A, Chen Y, Zhao X, Ji J, et al. Integrative genomic identification of genes on $8 p$ associated with hepatocellular carcinoma progression and patient survival. Gastroenterology. 2012;142(4): 957-966.e912.

34. Ally A, Balasundaram M, Carlsen R, Chuah E, Clarke A, Dhalla N, et al. Comprehensive and integrative genomic characterization of hepatocellular carcinoma. Cell. 2017;169(7):1327-1341. e1323.

35. Gao Q, Zhu H, Dong L, Shi W, Chen R, Song Z, et al. Integrated proteogenomic characterization of HBV-related hepatocellular carcinoma. Cell. 2019;179(5):1240.

36. Barrett T, Suzek TO, Troup DB, Wilhite SE, Ngau WC, Ledoux P, et al. NCBI GEO: mining millions of expression profiles--database and tools. Nucleic Acids Res. 2005;33(Database issue):D562-6.

37. Liu J, Lichtenberg T, Hoadley KA, Poisson LM, Lazar AJ, Cherniack AD, et al. An integrated TCGA pan-cancer clinical data resource to drive high-quality survival outcome analytics. Cell. 2018;173(2):400-416.e411.

38. Iorio F, Knijnenburg TA, Vis DJ, Bignell GR, Menden MP, Schubert M, et al. A landscape of pharmacogenomic interactions in cancer. Cell. 2016;166(3): 740-54.

39. Corsello SM, Nagari RT, Spangler RD, Rossen J, Kocak M, Bryan JG, et al. Discovering the anti-cancer potential of non-oncology drugs by systematic viability profiling. Nat Can. 2020;1(2):235-48.

40. Meyers RM, Bryan JG, McFarland JM, Weir BA, Sizemore AE, Xu H, et al. Computational correction of copy number effect improves specificity of CRISPR-Cas9 essentiality screens in cancer cells. Nat Genet. 2017:49(12): 1779-84.

41. Liberzon A, Subramanian A, Pinchback R, Thorvaldsdóttir H, Tamayo P, Mesirov JP. Molecular signatures database (MSigDB) 3.0. Bioinformatics. 2011;27(12):1739-40.

42. Yu G, Wang LG, Han Y, He QY. clusterProfiler: an R package for comparing biological themes among gene clusters. OMICS. 2012;16(5):284-7. 
43. Hänzelmann S, Castelo R, Guinney J. GSVA: gene set variation analysis for microarray and RNA-seq data. BMC Bioinformatics. 2013;14:7.

44. Wilkerson MD, Hayes DN. ConsensusClusterPlus: a class discovery tool with confidence assessments and item tracking. Bioinformatics. 2010;26(12):1572-3.

45. Wood RD, Mitchell M, Sgouros J, Lindahl T. Human DNA repair genes. Science. 2001;291(5507):1284-9.

46. Lange SS, Takata K, Wood RD. DNA polymerases and cancer. Nat Rev Cancer. 2011;11(2):96-110.

47. Knijnenburg TA, Wang L, Zimmermann MT, Chambwe N, Gao GF, Cherniack $A D$, et al. Genomic and molecular landscape of DNA damage repair deficiency across the Cancer Genome Atlas. Cell Rep. 2018;23(1):239-254.e236

48. Buisson R, Boisvert JL, Benes CH, Zou L. Distinct but Concerted Roles of ATR, DNA-PK, and Chk1 in countering replication stress during $S$ phase. Mol Cell. 2015;59(6):1011-24.

49. Rainey MD, Quachthithu H, Gaboriau D, Santocanale C. DNA replication dynamics and cellular responses to ATP competitive CDC7 kinase inhibitors. ACS Chem Biol. 2017;12(7):1893-902.

50. Wang D, Lippard SJ. Cellular processing of platinum anticancer drugs. Nat Rev Drug Discov. 2005;4(4):307-20.

51. Behan FM, lorio F, Picco G, Gonçalves E, Beaver CM, Migliardi G, et al. Prioritization of cancer therapeutic targets using CRISPR-Cas9 screens. Nature. 2019;568(7753):511-6.

52. Chan EM, Shibue T, MCFarland JM, Gaeta B, Ghandi M, Dumont N, et al. WRN helicase is a synthetic lethal target in microsatellite unstable cancers. Nature. 2019;568(7753):551-6.

53. Durbin AD, Zimmerman MW, Dharia NV, Abraham BJ, Iniguez AB, WeichertLeahey $\mathrm{N}$, et al. Selective gene dependencies in MYCN-amplified neuroblastoma include the core transcriptional regulatory circuitry. Nat Genet. 2018;50(9):1240-6.

54. Gonçalves E, Segura-Cabrera A, Pacini C, Picco G, Behan FM, Jaaks P, et al. Drug mechanism-of-action discovery through the integration of pharmacological and CRISPR screens. Mol Syst Biol. 2020;16(7):e9405.

55. Kim CM, Hwang S, Keam B, Yu YS, Kim JH, Kim DS, et al. Gene signature for sorafenib susceptibility in hepatocellular carcinoma: different approach with a predictive biomarker. Liver Cancer. 2020;9(2):182-92.

56. Rodon J, Soria JC, Berger R, Miller WH, Rubin E, Kugel A, et al. Genomic and transcriptomic profiling expands precision cancer medicine: the WINTHER trial. Nat Med. 2019;25(5):751-8.

57. Cardoso F, van't Veer L, Bogaerts J, Slaets L, Viale G, Delaloge S, et al. 70gene signature as an aid to treatment decisions in early-stage breast cancer. N Engl J Med. 2016;375(8):717-29.

58. Buus R, Sestak I, Kronenwett R, Ferree S, Schnabel CA, Baehner FL, et al. Molecular drivers of Oncotype DX, Prosigna, EndoPredict, and the Breast Cancer Index: a TransATAC study. J Clin Oncol. 2020. https://doi.org/10.12 00/JCO.20.00853.

59. Toledo LI, Altmeyer M, Rask MB, Lukas C, Larsen DH, Povlsen LK, et al. ATR prohibits replication catastrophe by preventing global exhaustion of RPA. Cell. 2013;155(5):1088-103.

60. Eykelenboom JK, Harte EC, Canavan L, Pastor-Peidro A, Calvo-Asensio I, Llorens-Agost $\mathrm{M}$, et al. ATR activates the S-M checkpoint during unperturbed growth to ensure sufficient replication prior to mitotic onset. Cell Rep. 2013;5(4):1095-107.

61. Canman CE. Replication checkpoint: preventing mitotic catastrophe. Curr Biol. 2001;11(4):R121-4.

62. Brooks K, Oakes V, Edwards B, Ranall M, Leo P, Pavey S, et al. A potent Chk1 inhibitor is selectively cytotoxic in melanomas with high levels of replicative stress. Oncogene. 2013;32(6):788-96.

63. Cole KA, Huggins J, Laquaglia M, Hulderman CE, Russell MR, Bosse K, et al. RNAi screen of the protein kinome identifies checkpoint kinase 1 (CHK1) as a therapeutic target in neuroblastoma. Proc Natl Acad Sci U S A. 2011; 108(8):3336-41.

64. Fang Y, McGrail DJ, Sun C, Labrie M, Chen X, Zhang D, et al. Sequential therapy with PARP and WEE1 inhibitors minimizes toxicity while maintaining efficacy. Cancer Cell. 2019;35(6):851-867.e857.

65. Wang C. CDC7 inhibition in PLC/PRF/5 cells. GSE183751, Gene Expression Omnibus. 2021. https://umw.ncbi.nIm.nih.gov/geo/query/acc.cgi?acc=GSE183751.

\section{Publisher's Note}

Springer Nature remains neutral with regard to jurisdictional claims in published maps and institutional affiliations.

\section{Ready to submit your research? Choose BMC and benefit from:}

- fast, convenient online submission

- thorough peer review by experienced researchers in your field

- rapid publication on acceptance

- support for research data, including large and complex data types

- gold Open Access which fosters wider collaboration and increased citations

- maximum visibility for your research: over $100 \mathrm{M}$ website views per year

At $\mathrm{BMC}$, research is always in progress.

Learn more biomedcentral.com/submissions 